\title{
La cuestión mexicana en el ambiente político español de mediados del siglo XIX: la obra de Pedro Pruneda
}

\section{Antonia Pi-Suñer Llorenz}

Como dueños del mundo parecísteis entre nosotros: habríamos dado muestras de no ser hombres, si no os hubiésemos rechazado por todos los medios que el legítimo amor a la independencia nos sugería.

Francisco Pi y Margall, Guatimozín y Hernán Cortés. Diálogos

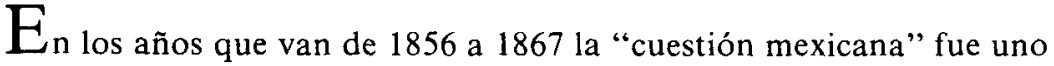
de los temas que constantemente preocupó a la opinión pública española ${ }^{1}$ y así lo muestran los editoriales en los periódicos, los discursos en las Cortes, los folletos de defensa o de denuncia y varias obras historiográficas. Estos años corrèsponden a los de mayor tensión en las relaciones entre México y España, las que llegaron a la ruptura definitiva en varias ocasiones durante este periodo. En general, la postura asumida por España hacia México era de poca simpatía, debido casi siempre al escaso conocimiento que se tenía tanto del país como de los problemas surgidos entre los dos gobiernos, y también, por qué no, a la tan decantada "honra española" que se sentía herida por la actitud que el gobierno liberal mexicano había tomado respecto a la metrópoli.

En este ensayo nos hemos propuesto mostrar que existió - aunque pequeña - una España liberal, democrática y republicana que vio con entusiasmo la lucha de México por su libertad, por su libre determinación y por la plena soberanía de su territorio. Prueba de esta actitud es la obra de Pedro Pruneda, Historia de la guerra de Méjico de 1861 hasta 1867,2 escrita aquel mismo año como testimonio de la simpatía y comprensión de la España republicana por la causa juarista, y que muestra cómo esta minoría se preocupaba por el destino de México y cómo su interés era más profundo que los discursos de Jules Favre en el seno del Parlamento francés o que los polémicos escritos de Edgar Quinet y Victor Hugo.

Pocos son los datos biográficos que tenemos de Pruneda ${ }^{3}$ pero su

\footnotetext{
1 "Cuestión mexicana" se llamó a los problemas entre los dos gobiernos, surgidos más que nada por razones financieras. Recuérdese también que por aquellos años la "cuestión de Oriente" era tema diario de discusión.

${ }^{2}$ Pedro Pruneda, Historia de la guerra de Méjico de 1861 hasta 1867, Madrid, Editores Elizalde y Cía., 1867. En México se hizo una edición facsimilar de la misma, con muy poca circulación, en 1973, en la Editorial Valle de México. Quiero aquí agradecer al doctor Miguel León Portilla el haberme prestado el libro en su primera edición y el haberme alentado a hacer un análisis del mismo.

${ }^{3}$ Los pocos datos que hemos encontrado son de la Enciclopedia Espasa-Calpe y de nuestras lecturas sobre el republicanismo español en el siglo pasado. Dos son solamente los ensayos que conocemos sobre la obra que nos proponemos analizar. El uno es de Miguel León Portilla, "El historiador Pedro Pruneda y su olvidada obra sobre la guerra de intervención" en Estudios de historia moderna y contemporánea de México, México, UNAM-IIH, 1967, vol. II, p. 139-145. El otro, de Vicente González Loscertales, Pedro Pruneda y la historiografía liberal española sobre México, conferencia inédita, dictada en 1980 en la ciudad de México en el Segundo Coloquio sobre Historiografia de México.
} 
nombre aparece junto con los de Pi y Margall y Emilio Castelar en aquellas obras que estudian el republicanismo español, aunque nunca llegase a figurar como estos dos prohombres, quizás por su muerte prematura. Sabemos que nació en 1830 y murió en 1869. Era aragonés y de tradición republicana, ya que su padre, Víctor Pruneda, desde la temprana fecha de 1843, promovió el republicanismo federal en su periódico El Centinela de Aragón. Pruneda hijo formó parte del núcleo demócrata - después republicano- que a partir de 1854 en Madrid fue tomando cada vez mayor importancia en el ámbito político español. Desde aquellos años -en que presentó su candidatura a las Cortes y que no ganó hasta su muerte, se convirtió en un activo militante por medio de sus artículos en lós periódicos más connotados del republicanismo español, como fueron La Discusión, La Democracia y El Pueblo. Su trayectoria ideológica dentro de aquel partido puede seguirse a través de sus colaboraciones, ya que si al principio trabajó junto con Pi y Margall, cuyo republicanismo era de corte más socialista y claramente federalista, se separó de él para seguir a Castelar, más individualista y menos radical. Participó como activista convencido en la sublevación del cuartel de San Gil, que anunciaba ya la "Gloriosa Revolución" de dos años después, a la que se entregó en cuerpo y alma. Murió, como dijimos, en 1869 , por lo que no pudo ver el advenimiento de la efímera República por la que tanto había luchado.

A pesar de lo poco que sabemos sobre Pruneda, creemos que su Historia de la guerra de Méjico surgió como arma política en el tenso ambiente que vivía España en vísperas de la revolución de 1868, misma que destronó por unos cuantos años a la monarquía borbónica. Es evidente que en ella el autor, a la vez que emprende la defensa de México, alaba a su presidente Juárez y enarbola la bandera de la no intervención y de la libre determinación de los pueblos, aprovecha la ocasión para acusar y denunciar al gobierno español tanto por haber permitido la "aventura mexicana" como por haber mostrado su servilismo ante el César francés. El que la obra queda inserta en una polémica nacional, y aun internacional, está claro desde las primeras páginas en que Pruneda, eufórico ante el triunfo juarista, proclama:

Hay en Europa cierta clase de escritores y hombres políticos que, ignorando o afectando ignorar las más triviales nociones sobre la organización de las Repúblicas americanas, aprovechan toda ocasión oportuna que se les presenta, ya para bosquejar un cuadro sombrío de su estado actual, ya para predecir con tono profético las calamidades que les reserva el porvenir... Ciegos ante el esplendor de la verdad, impasibles ante la evidencia de los hechos, estos escritores tienen un criterio especial para juzgar los acontecimientos y las cuestiones de América. ${ }^{4}$

La guerra de México se convierte pues en el símbolo de la libertad de los pueblos y sirve al pequeño grupo republicano español para echar en cara a los políticos coterráneos, y de otras latitudes, su ignorancia acerca de los países americanos y de su devenir histórico, al que espera un espléndido futuro. Por ello Pruneda emprende no solamente la historia de la guerra de intervención, sino que presenta un bosquejo, por lo demás muy bien logrado, de lo que ha sido la historia de México hasta 1861 .

${ }^{4}$ Pruneda, op. cit., p. III. 
Este afán por dar a conocer - y defender - el continente hispanoamericano no es exclusivo de nuestro autor, sino que ya se venía dando desde los años cincuenta, en que la cuestión mexicana se convirtió en tema de interés creciente. Recordemos que a partir de 1853 los problemas entre México y España se fueron agravando. En aquel año, y a escasos dos meses de su muerte, don Lucas Alamán, como ministro de Relaciones Exteriores, se negó a cumplir con la Convención de 1851 que estipulaba el pago de la deuda mexicana a los acreedores españoles. El hispanófilo ministro, quien a la vez buscaba un protectorado español para frenar el expansionismo norteamericano, consideró que las Convenciones que se habían firmadó sobre la supuesta deuda del gobierno mexicano con los españoles tenían su pecado original en la errónea interpretación del Tratado de Amistad firmado en 1836 entre los dos países, por lo que con un sólido alegato jurídico demostró la invalidez de la Convención de 1851 y se negó a cumplirla. ${ }^{5} \mathrm{El}$ asunto tomó entonces un cariz de enfrentamiento, y al llegar los liberales al poder se complicó aún más. En 1857 vino el rompimiento de relaciones entre los dos países y tanto aquí como allá la cuestión fue tema constante en el medio gubernamental, en los partidos políticos y en la prensa. Por lo que respecta a España, el tono que prevaleció en la opinión pública fue agresivo y despectivo en contra de México. Se pedia a voces plenas una intervención punitiva, y pocos eran aquellos que trataban de entender la situación y aun de dar razón al gobierno mexicano. Es pues necesario insistir en la defensa que de nuestra nación y de su política liberal hicieron algunos demócratas españoles, que si bien por aquellos años eran poco conocidos, poco tiempo después serían reconocidos como figuras de primer orden. Antes que nada queremos referirnos a don Francisco Pi y Margall, quien ante la posible intervención, sabiamente clamaba:

una nacionalidad recién formada mira con recelo y desconfianza a sus antiguos dominadores; ¡cómo no los ha de,temer y odiar si tiene motivo para creer que atentan contra su libertad y su vida? ${ }^{6}$

La simpatía y comprensión que mostró Pi por México no fue sólo circunstancial, sino que a lo largo de su vida don Francisco tuvo siempre un marcado interés por Hispanoamérica y fue uno de los pocos políticos españoles que vio, desde temprana hora, la independencia de Cuba como una obra de justicia. Su americanismo quedó plasmado en artículos de revistas tales como La América, La Ilustración Española y Americana y La Revista de Ambos Mundos, y en su propio periódico La Discusión. Asimismo, sus conferencias en el Ateneo de Madrid giraron muchas veces en torno a temas americanos; $y$, a fines de siglo, ya anciano, y con motivo de la erección en nuestro Paseo de la Reforma de la estatua de Cuauhtémoc, escribió un pequeño y delicioso

\footnotetext{
'Queremos hacer hincapié aquí en que fue el "conservador" Alamán el primero que se negó a cumplir con la Convención, seguido después, debido a su muerte, por Diez de Bonilla. Este hecho nos muestra dos cosas, por un lado, el afán de salvaguardar los intereses de la nación por parte de los grupos que han sido tildados de traidores por la historiografia oficial, y por otro, que Comonfort, al seguir la misma línea, no hacia nada nuevo sino que retomaba algo ya emprendido anteriormente.

${ }^{6}$ Citado en Tratado Mon-Almonte, estudio introductorio de Antonio de la Peña y Reyes, México, Secretaría de Relaciones Exteriores, 1925, p. xxxili.

'Francisco Pi y Margall, Guatimozín y Hernán Cortés. Diálogos, Madrid, Imprenta y Fundición de los hijos de J.A. Gaŕcía, 1899.
} 
diálogo entre Guatimozín y Hernán Cortés, ${ }^{7}$ canto a la libre determinación de los pueblos. Para terminar, no olvidemos que puso fin a su producción historiográfica con la Historia de la América Precolombina, tratado en el que quedó plasmado todo su interés por las culturas americanas. ${ }^{8}$ La misma postura que asumió Pi y Margall en la cuestión mexicana, y americana en general, fue la de Emilio Castelar, aunque más grandilocuente y seguramente menos profunda. Son famosos tanto sus discursos en las Cortes - recordemos que era un gran orador-, en los que exclamaba que "los héroes de la independencia de aquellos países son también nuestros héroes", con lo que hacía retumbar las paredes de aquellas conservadoras Cámaras, como sus colaboraciones panhispanistas en la misma Discusión, La Democracia y un sinnúmero de periódicos iberoamericanos, en las que insistía en que "necesitamos de América para dilatar nuestro espíritu". También en aquellos años tuvieron resonancia las intervenciones parlamentarias de Salustiano de Olózaga y de Juan Prim y Prats, intervenciones que pedían comprensión hacia México y cuya sinceridad se pudo constatar con la actitud adoptada por el general Prim en 1862. En este mismo sentido, la obra de Pruneda, por un lado reafirmó la justicia de la causa liberal mexicana y exhibió su admirable triunfo y, por otro, condenó el espíritu de intervencionismo del gobierno de Isabel II y denunció su servilismo ante Napoleón III. Recordemos que por aquellos años circularon con bastante éxito varios libros sobre México que defendían la causa intervencionista, apoyaban a O'Donell en sus aventuras americanas y denigraban tanto al gobierno juarista como al país en general. ${ }^{9}$

Si bien el título del libro es Historia de la guerra de Méjico de 1861 hasta 1867, la idea de Pruneda no fue sólo historiar la guerra de intervención sino dar toda una visión del desarrollo histórico de nuestro país, ${ }^{10}$ para mostrar que la libertad y la forma republicana de gobierno son algo inherente a la manera de ser, no sólo mexicana, sino americana. $\mathrm{Y}$ así es como la expresión "Ay de la libertad, si arrojada del viejo Continente, no pudiera refugiarse en las playas hospitalarias de la joven América"," se convierte en una de las tesis del libro. Como buen decimonónico, cree en el espíritu de los pueblos, que en el caso de México es republicano:

los pueblos, con su instinto, son el mejor maestro de los hombres de Estado, que en ese mismo instinto debieran aprender a gobernarles. Desde el primer momento, en 1824 como en 1867 , las masas consideraron como imposible el Imperio de Maximiliano, y la expresión popular de aquella opinión es hoy un hecho consumado. Méjico ha vuelto a la República. ${ }^{12}$

${ }^{8}$ Antoni Jutglar, Pi y Margall y el federalismo español. Madrid, Ediciones Taurus, 1975, vol. I, p. 197.

${ }^{9}$ Nos referimos a España y Méjico. Compendio de historia internacional de José G. de Arboleya, La Habana, Imprenta Cubana, 1861, Cuestiones de Méjico, Venezuela y América en general de José Ferrer de Couto, Madrid, Imprenta de Santa Coloma, 1861. El drama de alma y algo sobre Méjico de José Zorrilla, A.C., Madrid, 1865. El archiduque Maximiliano de Austria en Méjico de Martín de las Torres, Libreria de A. de San Martín, Madrid, 1867.

${ }^{10}$ El libro está dividido en dos grandes apartados, el primero dedicado a los antecedentes históricos desde la conquista hasta vísperas de la intervención, al que dedica unas setenta páginas. El segundo es la historia de la guerra, dividida en seis libros, complementado cada uno con varios y ricos apéndices documentales, y que en total consta de cerca de cuatrocientas páginas.

"' Pruneda, op. cit., p. X1.

${ }^{12}$ Ibidem, p. 437. 
Su afán es pues dar a conocer la historia de México y su constante lucha por la libertad y, a través de ella, reivindicar aquellos principios que el grupo demócrata-republicano español sostiene y que son considerados como un absurdo por sus enemigos políticos, quienes

niegan que haya sociedad, que haya gobierno, que haya civilización, que haya progreso en los pueblos regidos por instituciones democráticas y no comprenden que la humanidad pueda subsistir sin jerarquías, sin clases, sin aristocracia y plebe, sin opresores y oprimidos. ${ }^{13}$

Pruneda tiene pues todo un programa político que defender y desde las primeras páginas nos dice que su intención es demostrar que la democracia no es una aberración, que la república no es el origen perenne de trastornos y anarquia, que el respeto a la libertad individual no es un absurdo, que el sufragio universal no es una locura y que la igualdad civil no es ninguna utopía, como venían afirmando sus detractores. ${ }^{14}$ Le admiran la vitalidad de América y su tenacidad para vencer al enemigo cuando éste atenta a su libertad y por ello insiste en que México, en su lucha en contra de la intervención, ha dado una lección al mundo. La capacidad americana -ya sea hispana o anglosajona - de defender contra viento y marea los principios por los que él y sus correligionarios luchan tanto en las Cortes como en la prensa españolas, lo tiene impresionado

que la guerra estalie entre el norte y sur de los Estados Unidos, en nombre de un gran principio y para destruir una gran iniquidad y veréis cómo surgen como por encanto ejércitos de cien mil hombires que libran batallas comparadas con las cuales, las de Marengo y Austerlitz parecen insignificantes escaramuzas; que México vea amenazada su independencia y su libertad, y le veréis luchar con denuedo, disputando palmo a palmo la tierra sagrada de la patria, sin intimidarse por el número y la disciplina de los invasores, sin desmayar ante los continuados reveses, sin perder la fe ante las repetidas traiciones. ${ }^{15}$

Pruneda está convencido de que al continente americano le aguarda un grandioso futuro tanto por el dinamismo que caracteriza a los pueblos jóvenes como por los principios liberales que le son intrínsecos. Por ello aconseja a Europa que, en lugar de dedicarse a intervenir en América o a anatematizarla, deje de sentirse el centro del mundo -y por ende tan arrogante- y se preocupe, se interese y se informe más acerca de lo que realmente es este continente y de lo que aquí está sucediendo.

Es evidente que la no intervención y el pacifismo son el sustento ideológico de la obra. Don Víctor piensa que el principio rector de la política europea es el intervencionismo y que el belicismo no terminará hasta que deje de regir tal principio. El triunfo juarista marca pues un hito en la historia ya que ha demostrado que "el presente como el porvenir no pertenece ya a la intervención, que mata a la libertad, sino al sufragio universal, que nace de ésta, que le da fuerza". ${ }^{16}$ Estas palabras de Pruneda encajan perfectamente en la temática pro pacifismo

${ }^{13}$ Ibidem, p. 437.

${ }^{14}$ Ibidem, p. IV.

${ }^{15}$ Ibidem, p. 70.

${ }^{16}$ Ibidem, p. 75. 
que difundian los grupos democráticos europeos. En este sentido es interesante ver la coincidencia de fechas entre el fin del segundo imperio mexicano, la aparición del libro de Pruneda y la constitución en París de una Liga para la Paz en 1867. Ésta convocó, en aquel mismo año, un congreso en Ginebra, que fue presidido por las eminentes figuras del republicanismo italiano, Garibaldi y Mazzini. En dicha reunión nació la Liga Internacional de la Paz y de la Libertad, que tuvo una larga duración y a la que se adhirieron personajes de la talla de Victor Hugo, E. Quinet, Jules Simon, Jules Favre, Élisée Reclus, Stuart Mill, Bakunin y algunos españoles, entre ellos Emilio Castelar. ${ }^{17}$ Las resoluciones de aquel congreso y del siguiente, que se celebró al cabo de un año, fueron, entre otras, la no intervención, el desarme, el arbitraje internacional, el sufragio universal y la fórmula de organización politica de los Estados Unidos de Europa como muestra de la solidaridad y unión europea. ${ }^{18}$ Ignoramos si Pruneda estuvo presente en aquellos congresos, pero no nos cabe duda, según lo intuimos por su libro, de que estaba de acuerdo con todas sus propuestas. Formaba parte de aquellos utópicos y convencidos prohombres que creían firmemente que la fraternidad y solidaridad entre los pueblos era viable en este mundo. Esta convicción lo llevó a dar a su libro un tono moralizante a la vez que un tanto presuntuoso como suele ser el de aquellos que en un momento dado se sienten poseedores de la verdad, según lo ilustra la siguiente cita:

el principio de intervención ha formado por espacio de mucho tiempo la base del derecho público europeo. Hoy, ese principio, condenado por la historia, la filosofia, y más que todo por la experiencia, es anatematizado como inútil y perjudicial, por todos los espíritus superiores que se consagran a los estudios políticos. ${ }^{19}$

Este principio de la fraternidad entre las naciones lo llevó lógicamente a ver a México y a España como hermanas, relación que en el caso de estos dos países no obedecía sólo a principios ideológicos sino también a réalidades históricas. Por ello insiste todo el tiempo en que la decisión de intervenir en México fue del gobierno y no del "pueblo sensato español", quien se oponía a la expedición militar porque por un lado sentía que se iba a hacer la guerra a un pueblo hermano, "tan desigual además en poder y en influencia", y por otro presentía que iba engañado a "cumplir intenciones poco nobles y generosas". ${ }^{20} \mathrm{La}$ oposición entre el sentir del pueblo y el actuar del gobierno español también es otra constante del libro. Pruneda considera que la política española en la cuestión mexicana debía ser de conciliación y no de confrontación, de comprensión y no de intervención armada, porque "los actos de torpeza y de crueldad en otros tiempos en el nuevo mundo no tienen hoy otra enmienda ni pueden darle [a España] otra gloria que las que se originen de su prudencia y de su arrepentimiento". ${ }^{21}$ Todo un pasado de colonización y explotación habia

${ }^{17} \mathrm{Ma}$. Victoria López Cordón, El pensamiento politico internacional del federalismo español, Barcelona, Editorial Planeta, 1975, p. 44.

${ }^{18}$ Ibidem, p. 45.

${ }^{19}$ Pruneda, op. cit., p. 75.

${ }^{20}$ Ibidem, p. 75.

${ }^{21}$ Ibidem, p. 105. 
dejado tan mala imagen en México que había que cambiarla. Para lograrlo eran necesarias tres actitudes por parte de la antigua metrópoli; la primera, que aquellos españoles que viviesen en México dejasen de comportarse como "aves de rapiña que cogen su presa y se retiran a su nido a devorarlas", ${ }^{22}$ la segunda, que esos mismos grupos se abstuviesen de intervenir en la política mexicana, y la tercera, que el gobierno español comprendiese y apoyase la lucha de México por su libertad. En este sentido asienta que la labor de acercamiento entre los dos países ha sido reforzada por la actitud del general Prim, pero en ningún momento la obra se convierte en un panegírico del conde de Reus, como otras que circularon unos años antes. ${ }^{23}$ Es evidente que siente respeto por él, que admira "su gallardía, su savoir faire" y "la serenidad de espíritu que en todos sus actos le han distinguido", 24 pero en cambio se muestra muy mesurado en sus juicios políticos, en lo que notamos las diferencias ideológicas que había entre los republicanos y progresistas españoles, mismas que se hicieron patentes al estallar la revolución de 1868 .

En cuanto a la fraternidad entre México y España, principio tan decimonónico, vemos cómo en Pruneda se convierte casi en el de paternidad. $Y$ en ello nos damos cuenta que el hombre, por más que asuma posturas ideológicas, no puede desprenderse de toda una circunstancia histórica que lo ha nutrido y formado. Si bien defiende a México, lo alaba y le augura un espléndido futuro, en el fondo lo ve como un país inferior, al que no acaba de entender. Lo positivo que ve en el pueblo mexicano es producto de lo español, como lo evidencia la siguiente cita:

Hemos seguido con palpitante interés las alternativas de la heroica defensa de Puebla y nuestro corazón ha latido más de una vez con entusiasmo al recordar que los que de tal manera peleaban eran los hijos de aquellos que de nuestras playas llevaron al país de los aztecas su civilización y su actividad. ${ }^{25}$

Y en cambio del México "no español" nos dice:

La población de Méjico está compuesta de varias razas, inquietas y turbulentas, que infundẹn espanto por su crueldad en dondequiera que se presenten... Hay una clase de hombres, de que ni Europa ni en ninguna otra parte del mundo se tiene formada una cabal idea. Nos referimos a los llamados léperos o zaragotes, clase de proletarios que no se parecen a los de ningún otro pueblo, cuyo estado de miseria es debido únicamente a su indolencia, a su odio a la sujeción y al trabajo, a su apego al vicio. ${ }^{26}$

Por ello asienta que si bien es gracias a la tenacidad y convicción de Juárez que han triunfado finalmente los principios liberales, es necesario para el futuro progreso del país, que "estas razas se emancipen y se reconcilien con los mejicanos de raza española". ${ }^{27}$

${ }^{22}$ Ibidem, p. 173.

${ }^{23}$ Como por ejemplo, de Javier de Mendoza, La cuestión de Méjico y el conde de Reus, Madrid, Establecimiento Tipográfico de J. Casas y Díaz, 1859.

${ }^{24}$ Pruneda, op. cit., p. 142.

${ }^{25}$ Ibidem, p. 173.

${ }^{26}$ Ibidem, p. 86.

${ }^{27}$ Ibidem, p. 445 
Dada la ambigüedad que notamos en Pruneda respecto al país que defiende, nos preguntamos ¿qué piensa acerca de la conquista y la colonización? Es evidente que rechaza todo colonialismo opresor y explotador y en este sentido condena al español. Pero en cuanto a la conquista, a la que pone en el rango de epopeya, tanto por la intrepidez y valentía de los conquistadores como por la resistencia de Tenochtitlán -a la que sólo se puede comparar con las de Sagunto y Numancia-, considera que fue buena y mala. Buena porque introdujo el cristianismo, cuyos lazos de igualdad y de fraternidad unieron, por un lado, a los pueblos prehispánicos, entre los que existía un odio irreconciliable, y por otro, los civilizaron. Mala porque el gobierno y las clases poderosas desvirtuaron lo logrado y

convertido el imperio azteca en colonia española, fue explotada por sus ávidos dueños y durante tres siglos estuvo encorvada bajo el triple yugo del despotismo militar, del fanatismo religioso y del monopolio financiero, condenada a no producir por sí y para sí, languideciendo sobre un suelo fértil y bajo el más hermoso cielo de la tierra. ${ }^{28}$

Pruneda se nos muestra anticolonialista y anticlerical pero de ninguna manera anticristiano ya que está convencido de que la doctrina de Cristo ha sido un agente civilizador y propagador de las ideas de solidaridad y fraternidad. Esta fe en el cristianismo nos lo sitúa más como un demócrata cristiano que como un radical librepensador, como lo eran muchos de los republicanos contemporáneos.

Según dijimos más arriba, está convencido de que a México le espera un gran futuro. Habiendo triunfado los principios liberales y con algunos años de paz y de una dirección "inteligente y vigorosa" -que por supuesto ha de ser la de Juárez-, insiste en que nuestro país puede convertirse en una de las regiones más florecientes y prósperas del continente americano y así "crearse un gran Estado que sirva de norma y de ejemplo a las Repúblicas españolas de la América Central y de contrapeso al poder inmenso de los Estados Unidos, cuyas tendencias absorbentes es fuerza que se contengan y limiten". ${ }^{29}$

Llegamos aquí a otro punto interesante de la obra: la vecina república del norte. No cabe duda de que, como buen republicano federal, la admira. Encuentra en ella sabiduría política, excelentes instituciones - una vez abolida la esclavitud-y un enorme potencial económico. Reconoce además la pujanza y dinamismo de los pueblos anglosajones, para quienes está reservado el liderazgo del mundo futuro. Sin embargo, toda esta exaltada admiración por los Estados Unidos no lo ciega y se da cuenta del peligro que pueden representar -o que ya representan - tanto para Europa como para América Latina, y así advierte que son ya "la nación más poderosa de la tierra, cuyo poder y prosperidad amenazan de una manera imponente al viejo mundo". ${ }^{30}$ Por ello México tiene un papel tan importante, ya que si se descuida y no se organiza como un Estado fuerte y estable, puede convertirse en "el primer país de raza latina que caiga bajo la dominación de la raza anglosajona". ${ }^{31}$ También insiste, en tanto que español, en el peligro de que los Estados Unidos representan para Cuba y Puerto Rico, ya que

\footnotetext{
${ }^{28}$ Ibidem, p. 8.

${ }^{29}$ Ibidem, p. 445.

${ }^{30}$ Ibidem, p. 87.

${ }^{31}$ Ibidem, p. 91.
} 
es evidente el afán de aquéllos de hacerse de aquellas islas, y en este sentido, el que México caiga en manos norteamericanas supondría la absorción inmediata de las islas antillanas. Recordemos que este problema cuadrangular entre México, los Estados Unidos, Cuba y España estaba latente desde hacía varios lustros y que finalmente tomaría gran importancia con el estallido de la guerra de los Diez Años, en $1868,{ }^{32}$ por lo que la actitud de Pruneda nos hace ver que para el grupo en el que militaba, la amistad con México no sólo se debía a simpatías ideológicas sino también a intereses políticos.

Es interesante subrayar la admiración que siente por las razas germánicas, entre las que cuenta a los pueblos anglosajones, por lo que nos dice:

En cuanto a nosotros, los europeos de raza latina, basta de ridículos alardes de una superioridad que no tenemos, de amenazas que ya a nadie intimidan. Hace tiempo que nuestra estrella empezó a eclipsarse ante el esplendor de la que rige los destinos de las razas germánicas, más jóvenes y vigorosas que la nuestra, y más aptas para realizar el desarrollo de la humanidad en las futuras edades de la historia. ${ }^{33}$

El tono aleccionador y polémico de este párrafo es claro. Pruneda se nos muestra aquí como ferviente admirador de lo germánico, en lo que muestra influencia krausista, influencia por lo demás muy notable en el republicanismo español decimonónico, pero también es evidente el influjo de las ideas evolucionistas del momento al hablarnos de "las razas más aptas en el desarrollo de la humanidad".

La anglofilia de Pruneda es innegable así como también lo es su francofobia. Encuentra en la Gran Bretaña todas las virtudes, su sentimiento pro británico lo lleva hasta a afirmar que aquel país ha logrado un colonialismo benefactor. Insiste en que, al contrario de las antiguas colonias españolas, las británicas "bendicen a la metrópoli que con su actividad y con su sacrificio las ha levantado en un alto grado de prosperidad y de grandeza". ${ }^{34}$ En cuanto a Francia, el contraste resulta evidente, ya que no sólo arremete todo el tiempo en contra del "déspota y ambicioso César francés", sino que tampoco siente simpatía alguna por el pueblo de allende los Pirineos. Sentimos también que más lo ataca cuanto más pretende denunciar al gobierno español por someterse a los dictados de París. En este sentido la figura del general Prim, a la que ya hemos hecho referencia, le parece señera porque "sacrificó su gloria, su posición y su vida antes que acceder en mengua de su honor y de su honra a los deseos de Francia". ${ }^{35}$

No cabe duda de que así como detesta a Napoleón III, Pruneda se deja ganar por la figura de Maximiliano, quizás por su mismo pro germanismo. Resalta su trayectoria liberal en Europa, sus buenas intenciones para con México, pero también su carácter débil e inconstante. Lo llama siempre "el infortunado emperador", a quien el sino le tenía guardado un trágico fin. Insiste en el engaño de que fue víctima por parte de Francia, engaño que finalmente lo llevó a la muerte. A pesar

\footnotetext{
${ }^{32}$ Para mayor detalle sobre este punto ver Antonia Pi-Suñer, México y España durante la República Restaurada, México, Secretaría de Relaciones Exteriores, 1985.

${ }^{33}$ Pruneda, op. cit., p. 70.

${ }^{34} \mathrm{Ibidem}$, p. 75.

${ }^{35}$ Ibidem, p. 127.
} 
de sus esfuerzos y de haber adoptado muchas de las reformas dictadas por Juárez, su fracaso era de esperar pues la lucha de nuestro pais por la república y la independencia era algo inherente:

el elemento liberal de Méjico, que empapado en las doctrinas de la República por espacio de medio siglo; formaba la gran mayoría de la nación, no veía en Maximiliano sino el verdugo de las libertades y franquicia de la patria, y sus esfuerzos por desterrarle de un pueblo que a costa de tanta sangre y de sacrificios había conquistado su independencia, habían de ser heroicos e inagotables. ${ }^{36}$

Termina el autor mostrándonos que el triunfo de Juárez era lógico, pues los designios de Dios -o el destino- así lo tenían previsto, ya que estos designios son los de progreso, de libertad, de sufragio universal y de república. Pruneda, que sostiene que hay leyes históricas que rigen al mundo, en lo que notamos un rasgo positivista muy acorde con la época, nos acaba diciendo que "el dedo de Dios castiga al que intenta contrariar sus leyes, señalando a la vez la senda por donde debe dirigir siempre sus pasos la humanidad", ${ }^{37}$ lo cual nos muestra que su idea de la historia no era tan revolucionaria como los principios que defendía.

Después de haber analizado el pensamiento de Pruneda e insistido, por un lado, en la simpatía que sentía por la causa liberal mexicana y por otro, en el interés que tenía en atacar al gobierno español, hemos de reconocer que hay dos aspectos de su libro que nos han intrigado a lo largo de su lectura. El primero es la rapidez con que fue escrito y editado, y el segundo, la cantidad de datos fidedignos que maneja. Según el propio autor, se puso a escribir el primero de agosto, fecha que concuerda con lo que nos dice en su introducción acerca de la llegada de Juárez a la ciudad de México: "tal es la metrópoli de los aztecas. . la que acaba de recibir con palmas y flores, con aclamaciones de júbilo entusiasta al restaurador de la república", ${ }^{38}$ ya que efectivamente el presidente y su gabinete errantes entraron a la capital el 15 de julio de 1867 . En la conclusión, y como último dato cronológico, Pruneda hace referencia a la apertura del IV Congreso el día 20 de noviembre, lo que nos hace pensar que solamente tuvo, para la terminación y edición del libro, un mes escaso, puesto que la fecha de publicación es de aquel mismo año. No cabe pues duda de que la obra se hizo con prisa, pero es difícil aceptar que estuvo lista con tal rapidez. Hemos llegado a la conclusión de que probablemente el autor terminó su Historia en agosto-septiembre y que lo último que escribió fueron la conclusión y la introducción, en las que nos da las fechas arriba mencionadas y de las que una de ellas, por lo demás, está equivocada. ${ }^{39}$

${ }^{36}$ Ibidem, p. 306.

${ }^{37}$ Ibidem, p. 88.

${ }^{38}$ Ibidem, p. 445.

${ }^{39}$ Recordemos que según la convocatoria del 14 de agosto de 1867 para la elección de diputados, el IV Congreso se instalaría el 20 de noviembre. Lo más seguro es que Pruneda tuviese en sus manos dicho documento -o que alguien en México le hubiese informado de él, como lo veremos más adelante-y que pensase que efectivamente esa fecha se cumpliría. Pero debido a varias circunstancias, el Congreso no fue inaugurado hasta el 8 de diciembre, por lo que vemos que lo que afirma el autor era una șuposición y no una realidad y ello nos permite pensar que el libro se terminó en agosto o septiembre y no en noviembre-diciembre. Para más detalles sobre la convocatoria del 14 de agosto ver Jorge Tamayo, Benito Juárez, documentos, discursos y correspondencia, México, Libros de México, 1974, vol. XII, p. 883-884. 
Esto nos daría pues un lapso de tres meses para la edición, lo que ya sería más viable, pero que en cambio no quita la premura que tenía Pruneda en que apareciese su libro, como nos lo indica varias veces:

hemos reseñado los orígenes y conquista del vasto imperio de Méjico con la rapidez e incorrección que nos obligan los estrechos límites de la obra, la premura del tiempo y las poquísimas fuerzas con que contamos. ${ }^{40}$

¿A qué se debía pues tal prisa? Varias son las razones que podemos suponer pero ninguna nos parece definitiva, por lo que las proponemos como meras hipótesis. Si tomamos en cuenta que en 1867 se reunió el Primer Congreso de la Liga de la Paz y de la Libertad y el segundo al año siguiente, bien podría ser que Pruneda quisiese presentar entonces su libro, como claro testimonio de la lucha -y triunfo- de un pueblo por su libertad, y en este sentido podríamos comprender el tono triunfalista y aleccionador de la obra. Otra razón sería, como ya lo hemos dicho a lo largo de este ensayo, utilizar el fracaso de la intervención en México y el entreguismo del gobierno isabelino a la corte de Francia, para denunciarlo ante el pueblo español e incitarlo, en plena crisis política, económica y social, a la rebelión. Esto podría ser una posibilidad, sobre todo si tomamos en cuenta que en menos de un año estalló la revolución de 1868 . Una razón más podría ser, y quizás sea la más probable, que alguien en México estuviese interesado en dar la verdadera versión de lo que habían sido la guerra de intervención y el triunfo de Juárez, y que a través de Pruneda lo lograse tan rápidamente.

Esto nos lleva pues al último punto que queremos abordar. No cabe duda de que la obra es buena, de que tiene una cantidad enorme de datos y detalles sobre el acontecer diario de nuestro país en aquellos años, lo que nos hace pensar que difícilmente desde España se podía escribir tan veraz - y objetivamente- sobre lo que acontecía aqui. ${ }^{41}$ Tal parece pues que el autor tendría que haber sido testigo presencial de los hechos que narra. Cabría desde luego la posibilidad de que Pruneda hubiese estado en México, pero en contra de esta hipótesis tenemos el hecho de que él nunca áfirma haber estado aquí - no vemos además por qué tendría que ocultarlo-y que en 1866 participase en la insurrección de San Gil, y en 1868 en los preparativos de la revolución de septiembre, lo que le daría escaso tiempo para una estancia en nuestro país. ¿Quién fue pues su contacto -o informante- en México ${ }^{42}$ Alguien que vivió muy de cerca y además con intensidad los acontecimientos narrados, alguien al que algunas veces se le va el "esta tierra", alguien que describe con simpatía y emoción el desarrollo histórico de México y con objetividad la lucha contra la intervención. Las descripciones detalladas de las batallas, de las ceremonias religiosas con motivo de la llegada de Maximiliano, de la entrada triunfal de Juárez a la capital, y en fin de tantos otros hechos, son de alguien que no los leyó en uno o varios periódicos, sino de alguien que los vivió.

${ }^{40}$ Pruneda, op. cit., p. 25

${ }^{41}$ Después de haber analizado la prensa española de la época nos hemos dado cuenta de lo tergiversados que llegaban los datos a España y de lo imposible que era formarse una opinión tan clara de lo que estaba sucediendo.

${ }^{42}$ Niceto de Zamacois sostiene en su Historia de Méjico desde sus tiempos más remotos hasta nuestros días (Barcelona-Méjico, J.F. Parres y Cía., 1880, t. XIV, p. 480) que Pruneda "es un hombre supuesto por el verdadero autor" lo que en cierta manera confirmaría nuestra hipótesis de que alguien escribía desde México y Pruneda lo editaba en Madrid. Cf., t. XVI, p. 480. 
¿Quién podría pues haber sido su corresponsal? Hemos pensado en algunos nombres, y el que más viable nos parece es el de Anselmo de la Portilla, periodista español que llegó a México en 1840 y que, ya asentado aquí, se dedicó a través de su labor periodística e historiográfica a acercar a México y a España. Era un liberal moderado - recordemos que era muy amigo de Comonfort- y se movía en la elite política y cultural del México de aquella época. Estaba convencido de la necesidad de reconciliación de la sociedad mexicana y de la bondad y riqueza de su nuevo país. Bien podría haber sido que durante la intervención francesa se dedicase a informar y a enviar toda clase de documentos a Pruneda, para que éste escribiese su historia. Otra posibilidad, aunque difícil de comprobar, sería la de Balbino Cortés, cónsul español en Veracruz, de quien sabemos hay inéditos unos ricos apuntes sobre la intervención francesa en México. ${ }^{43}$ En cuanto a personajes mexicanos, podríamos pensar en Juan Antonio Mateos, que escribió dos novelas históricas sobre la intervención y el imperio, ${ }^{44}$ y era además un republicano convencido, pero de quien dudamos tuviese un contacto tan cercano y directo con un español de allende los mares. Sólo nos queda pues la opción de José María Lafragua, en quien vemos varias coincidencias con Pruneda. Su republicanismo, su liberalismo moderado, su afianzado nacionalismo, su convencimiento de la justicia de la causa juarista y su interés en difundir la historia de México bien podrian haberlo llevado a servir de corresponsal al historiador español. Recordemos además que su misión diplomática en España, aunque con sede en París, seguramente le permitió hacer buenos contactos con lọs demócratas hispanos, uno de los cuales podría haber sido Pedro Pruneda. Todas estas hipótesis quedan sin contestar pero pensamos que ofrecen una posible explicación.

Sea lo que fuere, no cabe duda de que el libro de Pruneda es digno de ser tomado en cuenta por todas las razones que hemos expuesto, y porque además es ameno, objetivo y rico en documentos que apoyan el texto. Cuenta además con datos muy interesantes que se han ido perdiendo al construirse el discurso oficial sobre aquel periodo. ${ }^{45} \mathrm{Y}$ en este sentido es de lamentar que no haya sido utilizado ni por los historiadores del México a través de los siglos, ni por Rivera Cambas en su largo estudio sobre las intervenciones en México, ni por el mismo Justo Sierra en su estudio sobre Juárez. Que el libro llegó a México en 1868 nos consta por una carta que el especialista en derecho internacional, el argentino Carlos Calvo, escribió desde París aquel mismo año dando las gracias al diputado mexicano Manuel Terreros, muy amigo del presidente, por haberle enviado el libro de Pruneda y un retrato del prócer oaxaqueño, y diciéndole que tanto el uno como el otro le habían parecido excelentes. ${ }^{46}$

${ }^{43} \mathrm{Cf}$. Vicente González Loscertales, Balbino Cortés y sus apuntes inéditos sobre la intervención francesa, conferencia dictada en diciembre de 1982 en la ciudad de México en el V Coloquio de Historiografia de México.

${ }^{44}$ Juan Antonio Mateos, El Cerro de las Campanas y El sol de mayo, México, Ed. Porrúa, 1985 (Col. Sepan Cuantos, núm. 193).

${ }^{45}$ Es muy interesante, por ejemplo, todo lo que se refiere a lo que Pruneda -o su informante- Ilaman "la conspiración del 15 de julio de 1866" que consistió en un complot de los colaboradores liberales del emperador, en contacto con Juárez y Santa Anna, para tomar el poder. La conspiración fue descubierta y tuvo como consecuencia el viraje, de nuevo, de Maximiliano hacia la reacción. El episodio relatado por Pruneda cuenta con varios documentos aclaratorios, op. cit., p. 364-367.

${ }^{46} \mathrm{~J}$. Tamayo, op. cit., vol. XIII, p. 774. 
Queda pues la Historia de la guerra de Méjico de 1861 hasta 1867 como prueba de una simpatía, comprensión y acercamiento muy profundos a México por parte de un republicano español. Como sabemos que el medio gubernamental hispano mostró casi siempre una enorme falta de sensibilidad hacia nuestro país y que por ende el clima para un acercamiento entre México y España nunca fue fácil, no nos cabe duda de que el libro que nos ha ocupado consiste en un admirable intento en este sentido. 